\title{
A EXPLORAÇÃO DE BRINQUEDOS POR CRIANÇAS EM EXPERIÊNCIAS LÚDICAS NA EDUCAÇÃO INFANTIL ${ }^{1}$
}

\author{
THE EXPLORATION OF TOYS BY CHILDREN IN LUDICAL \\ EXPERIENCES IN CHILDHOOD EDUCATION
}

\section{NIÑOS QUE EXPLORAN LOS JUGUETES EN EXPERIENCIAS DE JUEGO EN LA EDUCACIÓN INFANTIL}

\author{
Maria Elisa Nicolielo ${ }^{2}$ \\ Prefeitura Municipal de Pederneiras, SP, Professora de Educação Infantil
}

\begin{abstract}
Aline Sommerhalder ${ }^{3}$
Universidade Federal de São Carlos, Docente do Programa de Pós-Graduação em Educação (PPGE), Docente do Departamento de Teorias e Práticas Pedagógicas (CECH)
\end{abstract}

Resumo: Neste estudo objetivou-se compreender o modo como o brinquedo foi explorado por crianças da educação infantil em momentos de brincadeira livre em sala, e que funções foram atribuídas para esse objeto lúdico. Por meio da abordagem qualitativa, procedeu-se observação participante com 13 diários de campo, com discussão à luz de aporte teórico. Entre os resultados, verificou-se que o brinquedo, tanto o industrializado quanto o objeto transformado em brinquedo, fez-se consideravelmente presente nas brincadeiras, oportunizando o enriquecimento das experiências pelas crianças. Destacou-se necessária a qualificação da mediação docente no que se refere às manifestações de estereótipos de gênero em brincadeiras, a oferta de outros ambientes para brincar e a atenção pedagógica na disponibilização dos objetos lúdicos, a fim de contribuir para os processos de criação, exploração e enriquecimento das experiências das crianças.

Palavras-chave: Educação infantil. Crianças da primeira infância. Experiências lúdicas. Exploração de brinquedos. Interação.

\footnotetext{
${ }^{1}$ Pesquisa financiada pela Coordenação de Aperfeiçoamento Pessoal de Nível Superior (Capes).

${ }^{2}$ Mestre em Educação pela Universidade Federal de São Carlos; Graduada em pedagogia pela Universidade Estadual Paulista Júlio de Mesquita Filho.

${ }^{3}$ Doutora em Educação Escolar pela Universidade Estadual Paulista Júlio de Mesquita Filho; Mestre em Ciências da Motricidade pela Universidade Estadual Paulista Júlio de Mesquita Filho; Graduada em Pedagogia pela Universidade Estadual Paulista Júlio de Mesquita Filho.
} 


\begin{abstract}
It aims to understand how the toy was explored by children in early childhood education, in moments of free play in the classroom and what functions were assigned to this object. From a qualitative approach, participant observation was carried out with 13 field diaries. The qualitative analysis was carried out, with discussion in the light of theoretical contribution. Among the results is that the toy, both industrialized and the object transformed into a toy, became considerably present in the games, allowing the enrichment of the experiences, by the children. We emphasize the necessary qualification of teacher mediation regarding the manifestations of gender stereotypes in games. The provision of other play environments and pedagogical attention in the provision of play objects in order to contribute to the processes of creation, exploration and enrichment of children's experiences.
\end{abstract}

Keywords: Childhood education. Early childhood. Play experiences. Holding of toys. Interaction.

Resumen: Tiene como objetivo entender cómo el juguete ha sido explorado por los niños de preescolar en los momentos de juego libre en esa habitación y los roles se han asignado a este objeto. Enfoque cualitativo, se procedió observación participante con 13 diarios de campo. Hemos llevado a cabo un análisis cualitativo, con la discusión a la luz de apoyo teórico. Entre los resultados es que el juguete tanto industrializados como el juguete objeto transformado, se convirtió considerablemente presentes en la obra, proporcionando oportunidades para el enriquecimiento de experiencias para los niños. No es necesaria la calificación de la mediación docente en relación con las manifestaciones de los estereotipos de género en juego; la prestación de otros entornos para jugar y la atención pedagógica en la disposición de los objetos recreativos con el fin de contribuir a los procesos de creación, explotación y enriquecimiento de las experiencias de los niños.

Palabras clave: Educación infantil. Niños de la primera infancia. Experiencias lúdicas. Explotación de juguetes. Interacción.

\title{
1 INTRODUÇÃO
}

O presente artigo, resultante de uma pesquisa de pós-graduação acadêmica concluída e elaborada por pesquisadoras do Grupo de Estudos e Pesquisas sobre Processos Educativos de Crianças em Contextos, aborda a inserção do brinquedo por crianças em experiências lúdicas na educação infantil. O referido grupo faz parte do 
Centro de Pesquisa da Criança e de Formação de Educadores da Infância (CFEI) e tem como uma de suas linhas de pesquisa a produção de investigações sobre a ludicidade na educação de crianças.

A temática da ludicidade, apesar de regida na contemporaneidade por um número considerável de pesquisas, literaturas e outros materiais científicos, continua atual e demandando estudos científicos em razão da relevância que apresenta enquanto linguagem e experiência orientadora e articuladora da aprendizagem de crianças, especialmente na primeira infância.

Na compreensão da ideia de ludicidade, os brinquedos representam um estímulo para a imaginação do brincante. Não podemos negar nossa interação com os brinquedos, desde as primeiras relações estabelecidas com o outro adulto, seja por meio do corpo deste adulto, em brincadeiras iniciais estabelecidas entre bebê e mãe, seja pela apresentação de objetos considerados em nossa cultura e sociedade como brinquedos.

Esses objetos estão ou estiveram presentes na vida da maioria das pessoas, sejam estas crianças, pais, avós, sejam professores e adultos fabricantes desses materiais lúdicos. Entretanto, as maiores usuárias ou as mais interessadas pela exploração desses objetos brincantes são as crianças. Em sua maioria, elas se relacionam com os brinquedos quase que diariamente, entre eles brinquedos industrializados, artesanais ou objetos com outras funções e que são transformados por elas em brinquedos durante suas brincadeiras. Para Oliveira (2010), não se conhecem crianças que tenham dúvidas a respeito dos brinquedos e que desconheçam a sua importância em suas experiências lúdicas.

Muitas brincadeiras são estruturadas e se iniciam a partir de brinquedos que as crianças já possuem ou por aqueles que elas constroem, pensando em sua utilização na brincadeira. Compreendemos que o brinquedo se apresenta, de acordo com Brougère (2010), de três modos, sendo o primeiro o uso do corpo como um brinquedo. Segundo Sommerhalder e Alves (2011, p. 15), "O corpo é o nosso primeiro e mais versátil brinquedo." Com ele imaginamos as mais diversas situações para entrar no contexto da brincadeira, como mexer uma panela, sem ter em mãos qualquer utensílio, ou mesmo imitar um animal com o próprio corpo. Em bebês percebemos o corpo como brinquedo quando este se relaciona com a mãe, em práticas de amamentação ou quando descobre seu corpo, como os próprios pés.

No segundo modo, ele pode ser qualquer objeto, artesanal ou transformado em material lúdico por aquele que brinca, como uma caneta utilizada pela criança para representar um avião. Nessa situação, o objeto se torna brinquedo quando assume uma função lúdica liderada pela imaginação infantil e somente enquanto a brincadeira acontece. 
O terceiro modo é o objeto industrializado, produzido em larga escala pela indústria e reconhecido como tal pelo consumidor. Este sempre será visto como brinquedo dentro de uma situação lúdica ou não (BROUGÈRE, 2010).

Criado pela imaginação das crianças ou produzido industrialmente, o brinquedo é um suporte lúdico para as brincadeiras (KISHIMOTO, 2003). Ele é um dos meios para desencadear, instigar (e não formatar) a imaginação e a própria brincadeira. Por ser definido por sua função simbólica, ele permite às crianças estruturarem, modificarem e construírem as brincadeiras trazendo uma representação (e não a única possível) despertada pelo objeto. Assim, a brincadeira da criança está, em parte, ligada aos objetos lúdicos de que ela dispõe (BROUGÈRE, 2010), apesar destes não padronizarem ou delimitarem os modos de brincar ou o desenrolar da brincadeira. $\mathrm{O}$ brinquedo, industrializado ou não, é um estimulador e desafiador da imaginação das crianças e possibilita a elas a criação de inúmeras situações e brincadeiras.

Tendo como principal função o valor simbólico, por fazer parte da indústria cultural, o brinquedo é um objeto carregado de significados sociais e culturais, portanto é um objeto portador de cultura. "Através do brinquedo, a criança entra em contato com um discurso cultural sobre a sociedade, realizado para ela, como é feito, ou foi feito, nos contos, nos livros, nos desenhos animados." (BROUGÈRE, 2010, p. 69).

Brougére (2010) admite que o brinquedo pode ser compreendido como uma mídia, pois transmite às crianças conteúdos simbólicos e representações da sociedade que as cercam. Ao utilizarem os brinquedos e se apropriarem deles em suas brincadeiras, as crianças entram em contato com representações e significados pensados e destinados para elas sobre uma determinada sociedade e cultura. Essa representação não traz uma visão realista, “[...] mas uma imagem do mundo destinada à criança e que esta deverá construir para si própria.” (BROUGÈRE, 2010, p. 9). Entretanto, isso não deve ser considerado ruim, pois a presença de brinquedos industrializados nas experiências lúdicas da criança é importante por fazer com que, ao brincar, ela se aproprie desses significados. Muitas vezes, é por meio deles que as crianças conseguem se locomover, expressarem um interesse por algo ou mesmo obter apoio na compreensão dos objetos e ações da vida, como, por exemplo, entender o significado da prática de cozinhar com uso de fogão.

Como produto de uma cultura e servindo como ponte para o imaginário das crianças, mesmo o brinquedo industrializado, que já é portador de uma imagem, pode ser utilizado para outra função lúdica. "Ele traz para a criança um suporte de ação, de manipulação, de conduta lúdica, traz-lhe também, formas e imagens, símbolos para serem manipulados.” (BROUGÈRE, 2004, p. 41). Entre as corriqueiras menções e 
mesmo críticas feitas em relação a esses objetos fabricados em larga escala, é destaque o pensamento de que esse material restringe as experiências lúdicas, limitando ou mesmo formatando as possibilidades de brincadeiras.

Se considerarmos que o brinquedo é um objeto lúdico em que o valor simbólico predomina sobre sua função, a criança, ao se apropriar do brinquedo, poderá utilizá-lo da maneira como desejar, a partir de sua imaginação e das imagens que ele despertará. Essas imagens incentivarão, convidarão e permitirão dar sentido às ações lúdicas das crianças. No entanto, mesmo trazendo uma função explícita, o brinquedo industrializado é também um fornecedor de representações (em razão do seu valor simbólico).

Cabe dizer que essas representações são mutáveis, sendo comumente alteradas pelas crianças, que acabam por propor um outro jeito de explorar e utilizar esse objeto em suas brincadeiras, propondo novos usos a partir do já existente. "O brinquedo é, assim, um fornecedor de representações manipuláveis, de imagens com volume: está aí, sem dúvida, a grande originalidade e especificidade do brinquedo." (BROUGÈRE, 2010, p. 14). "É um universo espelhado que, longe de reproduzir, produz, por modificação, transformações imaginárias.” (BROUGÈRE, 2010, p. 20). Destaca o autor que manipular o brinquedo compreende manejar significações culturais de uma sociedade, e esse ato é uma aprendizagem para a criança, que transforma as imagens conforme seu interesse.

A presença dos brinquedos no cotidiano das crianças faz com que exista uma cultura adulta situada dentro da cultura lúdica. Isso ocorre pelo fato de que esses objetos são pensados pelos adultos para as crianças, sendo integrados de representações e conhecimentos que estes têm em relação a elas (BROUGÈRE, 1998). Nesse sentido, há um destaque para a influência da televisão e, com mais intensidade na atualidade, para as mídias digitais na cultura lúdica das crianças. Brougère (2010) ensina que essas mídias fornecem conteúdo e são suporte para as brincadeiras das crianças. Mas, o autor alerta que a criança não recebe de forma passiva esses conteúdos, uma vez que, em suas brincadeiras, ocorre um processo de apropriação deles de forma ativa. Tomando como exemplo a televisão, ele aponta que esse meio de comunicação influencia a imagem do brinquedo e o uso possível, incentivando seu consumo pelas crianças. Assim, o brinquedo se tornou uma indústria da imagem, tensionado pela televisão que é uma forma de mídia com comunicação direta para a criança (BROUGÈRE, 2004).

A televisão não se opõe à brincadeira, mas alimenta-a, influencia-a, estrutura-a na medida em que a brincadeira não nasceu do nada, mas sim daquilo com que a criança é confrontada. Reciprocamente, a brincadeira permite à criança apropriar-se de certos conteúdos da televisão. (BROUGÈRE, 2010, p. 57). 
Assim, mesmo que a cultura adulta interfira na cultura lúdica, ela continua sendo marcada pela ação da criança diante dessas propostas culturais (BROUGÈRE, 1998). Destacam-se como exemplos as crianças que transformam várias panelinhas em instrumentos de percussão, ou um carro com as portas abertas que possibilita brincar como se ele fosse um avião. As crianças ultrapassam a interpretação convencional acerca do brinquedo, manipulando-o livremente (OLIVEIRA, 2010). Nessa relação, elas externalizam seus pensamentos criando um universo da brincadeira para poder fazer aquilo que não é possível em sua realidade.

Consideramos que essa proposta de leitura do brinquedo é relevante, pois se confronta com um discurso corrente de que os objetos lúdicos industrializados restringem os processos criativos das crianças e as oportunidades de brincadeiras. Vale dizer que um brinquedo (industrializado ou não) é portador de qualidade quando atende às normas de segurança para uso e é um estimulador da imaginação infantil.

Quando pensamos na criança da primeira infância e em seus processos educativos, temos as interações e as brincadeiras como eixos norteadores das práticas pedagógicas na educação infantil (BRASIL, 2010). Entre as várias interações que a brincadeira pode proporcionar, Kishimoto (2010) destaca a que ocorre entre as crianças e os brinquedos, industriais ou não. Para a autora, essa interação é essencial para que as crianças conheçam e compreendam o mundo dos objetos e, consequentemente, a realidade ao seu redor.

Brincar desperta a curiosidade das crianças pela exploração de
objetos e brinquedos e as leva a ver o que se pode fazer com
cada objeto: uma bola pode rolar, pular, mas pode também ser
mordida para se experimentar a textura. A criança se encan-
ta quando descobre o botão que aciona a caixa de música e o
aciona repetidas vezes pelo prazer de ouvir o som. Encanta-se
quando vê reaparecer um objeto que enfiou na abertura de uma
caixa. Questiona a razão de a água não parar na peneira, o que a
faz pensar na hipótese de "segurar" a água com a mão debaixo
da peneira. É assim que as crianças vão aprendendo - experi-
mentando e repetindo várias vezes, em contato com os objetos
do mundo físico - o que cada coisa faz e o que se pode fazer
com cada coisa. (KISHIMOTO, 2010, p. 11, grifo nosso).

Como é bastante utilizado pelas crianças em suas brincadeiras, o brinquedo também contribui para a interação delas com seus pares. Durante as brincadeiras muitas situações de negociação, conflitos, fortalecimento de amizades, aprendizagens em relação a pedir e emprestar ocorrem pelo interesse por esses objetos. Brougère (2010) afirma que o desejo de utilização do brinquedo faz com que as crianças passem por 
experiências de posse e de negociações com outras crianças, fazendo com que elas se relacionem e interajam ainda mais durante as brincadeiras. Além da brincadeira, o brinquedo também acompanha as crianças em suas construções de relações sociais (SARMENTO, 2003).

Pode-se dizer que o brinquedo, seja industrializado, artesanal, seja produzido pela própria criança, é um material de grande relevância na educação infantil, não apenas por ajudar no desenvolvimento e aprendizagem, mas, também, por proporcionar que elas, a partir das relações estabelecidas durante as brincadeiras, vivenciem experiências de cultura e participem como protagonistas de seus processos de ensinar e de aprender.

Brougère (2004) pontua que o brinquedo participa da construção da infância, sendo ao mesmo tempo consequência, reflexo e uma de suas causas. Entretanto, o autor afirma que, para compreendermos e melhor pensarmos sobre o uso do brinquedo na educação infatil, é fundamental identificar o sentido que a criança atribui a ele, o que faz com ele e como se apropria dele.

No presente artigo teve-se como objetivo compreender o modo como o brinquedo foi explorado por crianças da educação infantil em momentos de brincadeira, e que funções foram atribuídas por elas para esse objeto.

\section{CAMINHO METOdOLÓGICO}

Realizou-se uma pesquisa de abordagem qualitativa (LUDKE; ANDRÉ, 2012; BOGDAN; BIKLEN, 1994) que teve como principal característica o aprofundamento no mundo dos significados das ações e relações humanas (MINAYO, 1994). Participaram do estudo um grupo de 14 crianças, com idade média de três anos, e a respectiva professora de uma instituição municipal de educação infantil de uma cidade do interior do Estado de São Paulo. Em relação à caracterização dos sujeitos da pesquisa, destaca-se que o grupo infantil era constituído por oito meninas e seis meninos, compondo uma turma inteira de matriculados no Maternal II, do período da manhã, e a respectiva professora. A escolha por essa turma decorreu do fato de que, nessa instituição, esta é a primeira faixa etária a ser atendida e, também, porque há uma compreensão social de que quanto menor é a criança, menos ela aprenderá e ensinará, fortalecendo exclusivamente práticas assistencialistas. A decisão pela realização do estudo com a turma que apresentava a menor faixa etária foi sustentada no interesse em contestar um discurso dominante de que crianças pequenas pouco podem participar e contribuir para o seu próprio processo de aprendizagem, uma vez que possuem saberes e conhecimentos insuficientes ou muito limitados para interações 
e trocas com pares e com os adultos. Além disso, houve uma recepção positiva da professora da turma para o desenvolvimento da investigação.

As crianças, em sua grande parcela, deslocavam-se para a instituição de van escolar, uma vez que as famílias trabalhavam na área do comércio. A maioria das crianças era curiosa, conversava bastante e interagia com facilidade. A professora, com 37 anos, é casada e tem dois filhos. Há quatro anos leciona na educação infantil da rede municipal de ensino e há três anos está na instituição pesquisada. Desde o primeiro contato com a professora, houve interesse dela em colaborar para a pesquisa.

Quanto à caracterização do contexto da pesquisa, a instituição municipal de educação infantil escolhida faz parte da rede municipal de ensino da Cidade de Pederneiras, interior do Estado de São Paulo. A aproximação com essa instituição ocorreu inicialmente por meio de convênio com o estágio curricular, sendo a maior em número de matrículas de crianças e considerada uma instituição de destaque em ações positivas nesse Município. Também foi realizado estudo anterior na mesma instituição, fortalecendo a aproximação das pesquisadoras com esse contexto educativo. A instituição localiza-se em um bairro central da Cidade, que possui característica comercial e se trata da escola mais antiga. Recebe crianças de bairros distintos, atendendo uma diversidade de público, captando várias comunidades, condições econômicas distintas, experiências e culturas diversas. $\mathrm{O}$ horário de funcionamento para as crianças no período da manhã é das $7 \mathrm{~h} 30$ às $11 \mathrm{~h} 30$ e à tarde é das $13 \mathrm{~h}$ às $17 \mathrm{~h}$.

A escola é ampla e possui nove salas, um espaço de sala para vídeo, uma brinquedoteca e uma biblioteca. Possui, também, um amplo pátio com área coberta e descoberta e um parque que fica em um espaço com árvores, gramado e possui vários brinquedos e dois tanques de areia. A escola conta também com cozinha, secretaria e banheiros adaptados para as crianças. No período da manhã, no ano em que este estudo foi realizado, as turmas estavam divididas da seguinte maneira: três salas de Maternal II (crianças de aproximadamente três anos), três salas de Jardim I (crianças de aproximadamente quatro anos) e três salas de Jardim II (crianças de aproximadamente cinco anos).

Na sala do Maternal II, na qual foi realizada a pesquisa, havia três mesas com seis lugares cada, a mesa da professora, quatro armários (dois para cada período), uma lousa, um ventilador, um espelho, uma lixeira e um baú com brinquedos. A sala estava bem colorida, com vários desenhos nas paredes e nos armários. Também havia cartazes, alfabeto, calendário e balões com a data dos aniversários das crianças da turma da tarde. $\mathrm{O}$ ambiente era fresco, arejado e com boa iluminação. A decoração da sala estava produzida com material emborrachado, com personagens das histórias infantis. 
Quadro 1 - Organização da rotina da sala

\begin{tabular}{|l|l|}
\hline Horário & Atividade \\
\hline $7 \mathrm{~h} 30$ às $8 \mathrm{~h}$ & Entrada e acolhida das crianças \\
\hline $8 \mathrm{~h}$ às $9 \mathrm{~h}$ & Vídeo \\
\hline $9 \mathrm{~h}$ às $9 \mathrm{~h} 30$ & Recreio \\
\hline $9 \mathrm{~h} 30$ às $10 \mathrm{~h}$ & Pátio \\
\hline $10 \mathrm{~h}$ às $11 \mathrm{~h} 10$ & Brincar na sala \\
\hline
\end{tabular}

Fonte: os autores.

Foram realizadas 13 inserções no cotidiano da turma em momentos de brincar livre, que ocorreram sempre às sextas-feiras, durante aproximadamente uma hora. A pesquisa de campo ocorreu tanto em sala quanto em outros ambientes da instituição que esse agrupamento infantil frequentou. Optou-se pelas sextas-feiras por ser o dia do brincar livre, no qual as crianças escolhem com o que, como e com quem brincar. Esse é o dia que as crianças também têm permissão e/ou são convidadas para levarem seus brinquedos para a instituição.

$\mathrm{Na}$ perspectiva de escutar e valorizar as vozes dos sujeitos da pesquisa e considerando a relevância das interações, do convívio e do diálogo para o desenvolvimento humano e para as aprendizagens, foi realizada observação participante das vivências em contextos lúdicos durante o período da última semana de julho e primeira semana de novembro. De acordo com Ludke e André (2012), a observação participante é uma técnica de coleta de dados importante na pesquisa qualitativa, pois possibilita ao pesquisador um contato pessoal com a situação pesquisada, fazendo com que ele experiencie diretamente essa situação e acompanhe as experiências dos sujeitos colaboradores do estudo.

Estabeleceu-se um processo de convivência com as crianças e com a professora, permeado pelo diálogo, respeito e confiança. Nesse sentido, Oliveira (2009) traz a expressão "convivência metodológica" para apontar a necessidade de essa convivência se caracterizar como um elemento metodológico da pesquisa. Corroborando essa proposta, e a partir do que Silva, Barbosa e Kramer (2008) apontam, entendeu-se que, ao se inserir em um grupo de crianças e reconhecê-las como sujeitos e atores sociais, também foi fundamental o processo de escutar, de modo sensível e ativo, o que as crianças tinham para dizer por meio de suas diversas linguagens, em especial pela linguagem do brincar. Para Pereira, Salgado e Jobim e Souza (2009, p. 1023):

Tratando-se de pesquisa com crianças, esse modo de produzir conhecimento se traduz no processo de pesquisar com o outro - a criança - e não mais pesquisar sobre ela, buscando uma 
definição sobre a infância que silencia diante do confronto e das tensões entre as imagens que crianças e adultos constroem de si e do outro.

A proposta de valorizar o ponto de vista infantil não individualiza o retrato da realidade, pois brincar é um ato social e o contexto lúdico investigado é marcadamente regido por relações humanas estabelecidas entre crianças e adultos (como a professora) e entre elas. Ter atenção ao que as crianças estavam fazendo, nas interações entre pares e com a professora, observar os gestos e ouvir as conversas implicou assumir uma postura de quem se reconhece diferente delas, mas, ao mesmo tempo, interessado e curioso em conhecê-las melhor. Essa atividade de pesquisa exigiu postura humilde do adulto pesquisador, com a consciência de que não conhece tudo sobre as crianças e as relações humanas, e, por isso, propõe-se a estar junto e acompanhar essa prática social de brincar.

Para o pesquisador, trata-se de procurar entender, a partir do ângulo da criança, o que de fato ela está dizendo, sem colocar a sua interpretação como sendo a dela. Isso requer um reconhecimento dos limites do discurso e a consciência de que para alcançar a verdadeira compreensão deve abrir mão do seu ponto de vista, ou seja, do seu julgamento. Só assim, poderá se aproximar da experiência singular que o outro nos proporciona [...] (PEREIRA, SALGADO, JOBIM E SOUZA, 2009, p. 1033).

No primeiro dia de inserção, realizamos um processo de anuência de pesquisa em relação às crianças. Esse processo foi gravado e constitui-se em uma conversa com as crianças explicando o estudo que seria realizado. Foram respeitados todos os cuidados éticos no que se refere às autorizações para a realização da pesquisa, ao consentimento de participação, à confidencialidade dos dados e ao anonimato dos participantes por meio de nomes fictícios escolhidos pelos próprios sujeitos desta pesquisa. Destaca-se que a pesquisa foi aprovada pelo Comitê de Ética em Pesquisa com Seres Humanos da Universidade Federal de São Carlos, SP.

Foram realizados registros em diários de campo a partir das observações participantes. Essa técnica de registro se caracteriza por ser um relato escrito daquilo que o pesquisador viu, ouviu, acompanhou, experienciou e pensou no decorrer da pesquisa, buscando conhecer e dissecar a realidade encontrada (BOGDAN; BIKLEN, 1994). A escolha por esse instrumento decorreu do fato de que o diário de campo é um auxílio importante para a memória do pesquisador, pois aspectos cruciais da pesquisa podem ser revelados a partir desse instrumento, permitindo um olhar aprofundado para a análise da situação pesquisada (COSTA, 2002). Ao término da pesquisa de 
campo foram elaborados 13 diários, um para cada inserção/dia de observação participante realizada. A análise dos dados foi realizada qualitativamente e teve como inspiração para organização a análise de conteúdo, proposta por Bardin (2009), e a discussão foi realizada à luz do referencial teórico escolhido.

\section{RESULTADOS E DISCUSSÃO}

\subsection{PROCESSOS DE INTERAÇÃO DAS CRIANÇAS COM OS BRINQUEDOS: UMA LEITURA DOS EPISÓDIOS LÚDICOS}

A partir da proposta deste estudo, são apresentados e discutidos os resultados referentes ao eixo de análise Interação com os brinquedos e os respectivos temas: exploração dos brinquedos industrializados, exploração de objetos e estereótipos de gênero. Esses temas foram construídos a posteriori, a partir das leituras e análise dos diários de campo. A primeira etapa desse processo foi caracterizada pela leitura flutuante, ou seja, uma leitura geral de todos os diários de campo. Após leitura e escolha pela utilização de todos os documentos diários como registros de dados, fizemos a exploração de cada material realizando uma nova leitura, mais densa, dos 13 diários de campo, a fim de identificar acontecimentos que apareceram a partir do critério da frequência. Durante essas leituras fizemos marcações em destaque nos diários, objetivando levantar e organizar os acontecimentos que se aproximaram e a frequência dessas aparições. Realizadas as marcações, foram identificados os temas que tiveram significativa frequência. Cabe destacar que o eixo de análise também foi construído a posteriori, a partir da aglutinação por proximidade dessas temáticas, resultando na finalização da organização dos resultados.

Os resultados mostraram que, em sua maioria, as crianças brincaram com os chamados jogos simbólicos, ou seja, que se apoiam na imaginação e no faz de conta. Como suporte para essas brincadeiras as crianças utilizaram brinquedos industrializados, trazidos por elas e oferecidos pela professora, e objetos disponíveis na sala. Os brinquedos levados para a escola com maior frequência foram industrializados: bonecos personagens de super-heróis, bonecos personagens de desenhos animados, carrinhos, animais de plástico, bonecas, animais de pelúcia, aviões, trens e boneca Barbie. Entre os disponibilizados pela professora, os industrializados foram: massinha de modelar, jogo de panelinhas, carrinhos e espátulas coloridas. Também tivemos brinquedos elaborados a partir de embalagens variadas de iogurtes e potes de plástico de requeijão (todas limpas), que foram disponibilizados pela professora na sala e esta- 
vam organizados em uma caixa de papelão. Cabe dizer, então, que para a criança um objeto pode ser transformado em brinquedo, desde que assuma uma função lúdica na brincadeira.

Iniciamos pelos resultados decorrentes do tema exploração dos brinquedos industrializados. A partir da exploração desses brinquedos, compreendemos como as crianças se apropriaram, modificaram e os utilizaram em suas brincadeiras. As crianças da primeira infância, como no caso desta pesquisa, interessam-se por utilizar os brinquedos a partir de sua imaginação e não de acordo com o que o brinquedo propõe, diferentemente das crianças maiores (BROUGÈRE, 2004).

\footnotetext{
Sentadas à mesa Rebeca e Gabriela brincam juntas com os brinquedos Woody e Jessie (personagens do filme Toy Story). Sento junto com elas para observá-las e Rebeca me mostra a boneca Jessie.

Pesquisadora: A perna dela quebrou. Vamos levar para o hospital, chama a ambulância.

Rebeca vai até a outra mesa e pegas duas barbies. Uma utiliza para ser a ambulância e a outra a médica. Coloca a Jessie em cima da "Barbie ambulância" e imitando o som de uma ambulância movimenta a Barbie como se estivesse andando.

Rebeca: "OOIIOHH, IIOHH".

Eu conserto a Jessie e elas voltam a brincar como no início (Diário de Campo n. 3, informação verbal).
}

Diante de tal situação e da maneira como Rebeca se apropriou da Barbie, compreendemos que mesmo sendo industrializado, com funções estabelecidas a priori, imagem e características, o brinquedo pode ser utilizado de várias maneiras pelas crianças. A Barbie não lembra uma ambulância, automóvel ou qualquer outro meio de transporte, mas a necessidade do objeto lúdico nessa brincadeira fez com que Rebeca imaginasse que a boneca fosse ambulância. Nesse sentido, mesmo que o brinquedo venha pronto, com várias funções, é o uso espontâneo da iniciativa da criança que prevalece (BROUGÈRE, 2004). Para o autor, ao brincar, a criança se apropria do brinquedo, o manipula e, ao fazer isso, o transforma, dando-lhe novos significados. “Com efeito, a imagem do brinquedo não é qualquer imagem: ela deve ser manipulável no interior da atividade lúdica da criança e corresponder à lógica da brincadeira." (BROUGÉRE, 2004, p. 18).

Quando Rebeca transformou imaginariamente a boneca Barbie em ambulância, ela interagiu com o objeto, mas fez isso a partir das características de ambulância e não de boneca, o que compreende um novo significado atribuído a esse objeto. Essa relação é importante, pois a criança vivencia uma situação transitória entre sua 
ação com objetos concretos e sua ação com os significados, possibilitando que, no futuro, ela saiba se desvincular de situações concretas (HORN, 2004).

Em outra cena lúdica, Ben 10 e Homem Aranha utilizaram os brinquedos de várias maneiras:

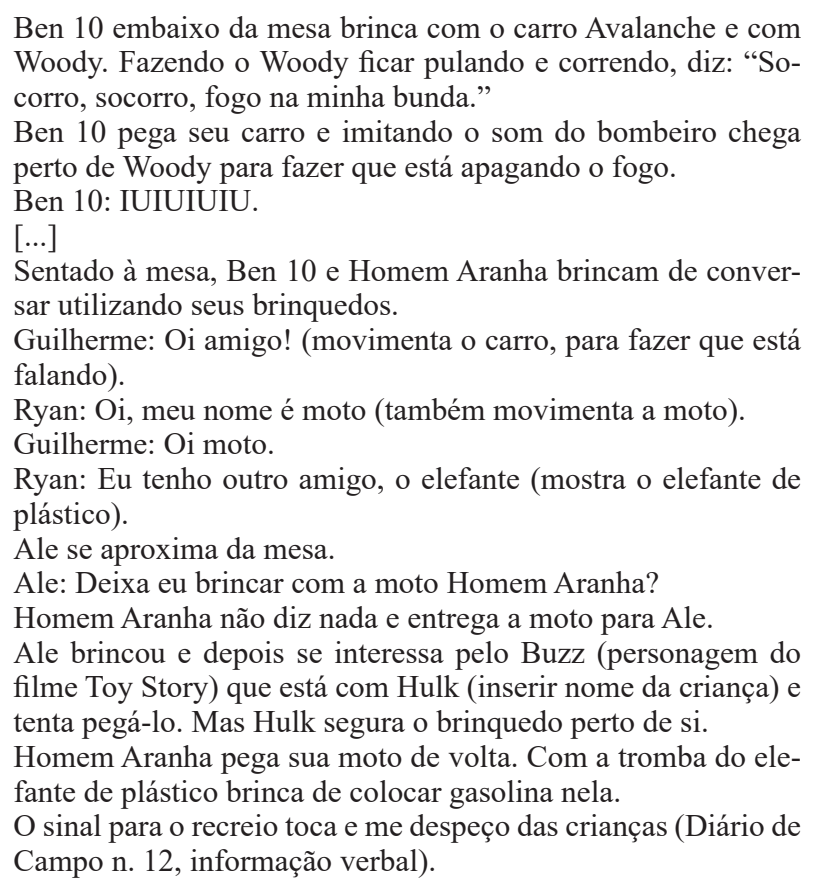

Mais uma vez, as crianças utilizaram os brinquedos a partir do interesse que tinham na brincadeira de acordo com seu interesse, necessidade, fantasia e imaginação. Brougère $(2010,2004)$ destaca que o brinquedo serve à brincadeira, que é uma atividade livre. "E, na verdade, o que caracteriza a brincadeira é que ela pode fabricar seus objetos, em especial, desviando de seu uso habitual os objetos que cercam a criança.” (BROUGÈRE, 2004, p. 15). Nesse sentido, continua Brougère (2004, p. 14) questionando: "É possível, a priori, definir o que é brincar com uma bonequinha ou um automóvel em miniatura?”

Na cena em que utilizaram os brinquedos para conversar, as crianças deram ao Ben 10 e ao Homem Aranha características humanas, ou seja, utilizaram a personificação. Sobre isso, Leontiev (2001) destaca que mesmo que as crianças imaginem várias situações a partir de um objeto, transformando este de acordo com sua criatividade, elas sabem que o objeto é real e conhecem as características dele. Para o autor, a ação das crianças sempre corresponde exatamente ao objeto com o qual elas estão brincando. 
Diante das necessidades e interesses, novas funções e significados são atribuídos, pelas crianças aos brinquedos. Brougère (2004) destaca que por mais que ele já venha com um significado, o brinquedo gera ações heterogêneas que ocorrerão de acordo com o contexto das crianças, seus conhecimentos, experiências, maneiras de ver o mundo. Assim, não é apenas o contexto da brincadeira que as fazem explorar os brinquedos de diversas formas, mas também o que elas carregam de experiências de outros momentos e vivências.

Durante os momentos de brincar livre, as crianças também brincaram com objetos variados que estavam na sala. Sobre isso, trazemos os resultados do tema exploração de objetos.

As meninas brincam de fazer comidas, utilizando o suporte da lousa para colocar as embalagens de iogurte e requeijão e panelinhas, pratos, colher, garfos de brincadeira.

Rebeca: Eu fiz torta de morango.

Moranguinho oferece uma embalagem de requeijão para mim.

Pesquisadora: O que é isso?

Moranguinho: Refrigerante.

Eu faço que bebo o refrigerante e devolvo o copo.

Pesquisadora: HUUMM que delícia, obrigada!

Josi leva bebida de mentirinha em um copo de iogurte para a professora que está sentada à sua mesa. Em seguida traz para mim suco de maracujá de mentirinha na mesma embalagem utilizada anteriormente

Pesquisadora: Obrigada. (Diário de Campo n. 2, informação verbal).

Josi está em pé na sala segurando um ursinho de pelúcia e com um gloss faz que está dando mamadeira a ele. Ela vem em minha direção e oferece o ursinho.

Josi: Dá mamadeira pra ele.

Eu pego o ursinho no colo e realizo a ação de dar mamadeira utilizando o gloss de Josi.

Entrego o ursinho para Josi.

Pesquisadora: Acho que ele quer dormir.

Josi balança o ursinho, fazendo gestos de ninar e depois o coloca em uma cadeira (Diário de Campo n. 3, informação verbal).

Josi, Ana e Rebeca estão desenhando nos cadernos que a professora entregou, sentadas à mesa. Durante a brincadeira, Josi se levanta e pega um objeto retangular cor de rosa da linha de bonecas Monster High. Volta para a mesa e, utilizando esse objeto como celular, inicia uma conversa.

Josi: Alô amiga! Eu estou trabalhando. Ah é... ela está lá em cima. Mãe! (se dirigindo a Ana) tem uma amiga que está lá em cima. Para de falar e volta a desenhar (Diário de Campo n. 6, informação verbal). 
As embalagens de diversos materiais disponibilizadas pela professora foram bastante utilizadas pelas meninas no contexto da brincadeira de casinha como apoio para imaginarem que estavam fazendo comida. Os copos vazios de iogurte serviram de copo para muitas bebidas. Josi transformou seu gloss em mamadeira e um objeto retangular, em telefone. A brincadeira é caracterizada, em outros aspectos, por ser livre e, portanto possibilitar que a criança faça o que lhe interessar. Assim, elas podem criar seus objetos ou explorá-los de modo diferente do uso habitual.

Há na sociedade uma ideia de que brinquedo é somente aquele fabricado, comercializado, industrializado e que brinquedo bom é aquele com muitas funções, cheio de dispositivos. Entretanto, muitas vezes, ao ganhar um brinquedo a criança prefere brincar com sua embalagem em vez do próprio brinquedo, mas, mesmo assim, essa embalagem não é vista como um brinquedo pelos adultos e não demora muito a ser jogada no lixo. Sobre isso, Sommerhalder e Alves (2011, p. 15) apontam que os objetos ou brinquedos mais simples produzem um efeito mais significativo em termos de aprendizagem e desenvolvimento da criança e que "a beleza e qualidade do brinquedo decorre de sua capacidade de instigar a imaginação da criança, e não da possibilidade de imitação de gestos."

Para finalizar a discussão, apresentamos o tema estereótipos de gênero.

Miguel levou para brincar um chapéu de plástico vermelho com um símbolo que indicava ser de xerife, um rádio de comunicação e um martelo. Ele e Ben 10 brincam embaixo da mesa com o chapéu e o rádio. Ana pega o martelo que está em cima da mesa e diz:

Ana: Eu bato forte com o martelo. Ele é muito forte.

Ben 10, com o chapéu de xerife na cabeça, sai debaixo da mesa e tira o martelo de Ana dizendo: "Menina não pode trabalhar."

Ana não diz nada e vai brincar de passar batom com Rebeca e Flor.

Ben 10 volta para debaixo da mesa com o martelo nas mãos (Diário de Campo n. 4, informação verbal).

Compreendemos que a associação feita por Ben 10 entre o brinquedo martelo e o fato de que menina não pode trabalhar pode ter sido realizada em razão das experiências vivenciadas por ele na família ou em outros contextos sociais ou por presenciar sempre meninos brincando com brinquedos considerados, em nossa cultura, como aqueles indicados para o universo masculino. Sobre isso, Finco (2007) aponta que as marcas de gênero nos corpos infantis são impostas a partir das expectativas dos adultos em relação às crianças. Dessa maneira, sendo um produto elaborado e pensado pelos adultos a partir de referência de cultura, o brinquedo também contribui para indicar para as crianças as distinções de gênero. Ao analisarmos o brinquedo e 
compreendermos que esse objeto é carregado de significados sociais e culturais e que ele pode estar atrelado à construção de ideias e valores nas crianças, compreendemos que o brinquedo interfere intencionalmente de maneira diferente na vida de meninas e meninos. Ao interferir na brincadeira de Ana, Ben 10 pode ter delimitado as possibilidades criativas dela com o martelo, além de contribuir para que Ana construísse uma visão estereotipada de gênero, transmitindo esse valor cultural para outras crianças.

Sobre brincadeiras e gênero, Brougère (1998) considera existir uma cultura lúdica de gênero, mostrando que elas são diferentes para meninos e meninas.

As culturas lúdicas não são (ainda?) idênticas no Japão e nos Estados Unidos. Elas se diversificam também conforme o meio social, a cidade e mais ainda o sexo da criança. É evidente que não se pode ter a mesma cultura lúdica aos 4 e aos 12 anos, mas é interessante observar que a cultura lúdica das meninas e dos meninos é ainda hoje marcada por grandes diferenças, embora possam ter alguns elementos em comum.

O autor destaca, ainda, que a cultura lúdica não está isolada da cultura geral, pois sofre influência dela. Nesse contexto, a visão dos familiares, as proibições dos professores, os espaços na escola, na casa e em outros lugares de convívio da criança influenciarão essa experiência lúdica.

Desde bebês, as crianças recebem brinquedos distintos. Ao observarmos as "escolhas" de meninas e meninos, percebemos como elas vão sendo influenciadas pelas famílias, mídias e outras crianças. Cabe dizer que essas escolhas são limitadas dentro de opções predeterminadas e decididas, muitas vezes, inicialmente por um adulto. Para as meninas, um universo cor-de-rosa com brinquedos relacionados à vida doméstica (panelinhas, kit de limpeza, ferro de passar roupa) e maternidade (bonecas, bebês); para os meninos, brinquedos relacionados à vida fora de casa, ao trabalho, elementos científicos e poder (carrinhos, martelos, armas, objetos de laboratório). Com esse padrão que diferencia em tudo o sexo feminino do masculino, Finco (2007) afirma que meninas e meninos estão sendo privados de determinadas formas de expressão e, com isso, deixam de exercitar suas vontades e acabam inibindo e limitando suas forças imaginativas e criativas.

Em outra cena lúdica, Ale se negou a entregar seu brinquedo (personagem do desenho Ben 10) para Daiane, argumentando que era de menino.

Durante a brincadeira, Homem Aranha pega o brinquedo (personagem do desenho Ben 10) que Ale trouxe e entrega a ele.

Homem Aranha: A Daiane queria pegar, a Daiane queria pegar. Depois vem e fala para mim. 
Homem Aranha: A Daiane queria pegar o brinquedo do Ale. Aí eu peguei e dei pra ele.

Ale: Não dou pra ela porque é de menino.

Pesquisadora: Por quê?

Ale: Porque é de menino.

Pesquisadora: Então eu não posso brincar?

Ale: Não!

Pesquisadora: Por quê?

Homem Aranha: Menina brinca de boneca (Diário de Campo n. 13, informação verbal).

Brougère (2010) anuncia que os estereótipos de gênero nos brinquedos estão relacionados ao fato de que os brinquedos de meninas se restringem ao universo feminino e o de meninos, ao universo masculino. Quando as crianças utilizam o brinquedo, elas estão manipulando os códigos culturais e sociais que ele transmite. Assim, para Ale, Ana não podia brincar com seu brinquedo, pois este não representa seu universo, mas, sim, o de luta, o de superpoderes, condizentes com o universo masculino.

$\mathrm{Na}$ maioria das situações, as crianças escolheram os brinquedos que socialmente são indicados para seus gêneros, principalmente os meninos que têm uma escolha mais restrita, pois preferem brincar com brinquedos destinados ao universo masculino, não preferindo o brinquedo do outro (BROUGÈRE, 2004). Esse dado também se fortalece com os resultados da presente pesquisa, pois verificamos que foram mais as meninas que pegaram os brinquedos dos meninos ou participaram de suas brincadeiras. Contudo, Brougère (2004) salienta que, por mais que as meninas brinquem com os meninos e com seus brinquedos, suas brincadeiras continuarão tendo temáticas familiares e relacionamentos, sendo menos ligadas a lutas e guerras.

A escolha feita pelas crianças apenas pelos brinquedos vistos por elas e pela sociedade como sendo para seu próprio sexo não é de todo ruim, pois quando a criança escolhe o brinquedo destinado para seu próprio sexo ela está construindo sua identidade e seus próprios papéis para ser percebida enquanto sujeito. Consideramos também que não é apenas a questão de gênero que influencia na escolha dos brinquedos, mas todo o contexto de vida das crianças (idade, pertencimento social, meio cultural, recursos econômicos) (BROUGÈRE, 2004).

Esse retrato que trazemos para discussão ficou evidenciado em momentos de brincar desse grupo de crianças, e as relações de gênero ocorreram de maneira diversa, dependendo do contexto das brincadeiras, dos brinquedos disponíveis e da dinâmica que o brincar assumiu para as crianças nos dias de observação participante. 


\section{CONSIDERAÇÕES FINAIS}

Os resultados anunciaram como foram importantes os brinquedos, sejam eles industrializados ou não, para as brincadeiras dessas crianças. Na maioria das cenas lúdicas, eles estiveram presentes e desencadearam as brincadeiras e incentivaram as crianças a modificá-las, evidenciando a compreensão de Kishimoto (2003) sobre o brinquedo como objeto, suporte da brincadeira.

As crianças se apropriaram dos brinquedos de acordo com a proposta e contexto de suas brincadeiras e necessidade de um suporte para aproximação, da melhor forma, da realidade. O brinquedo é uma ponte para o imaginário da criança, ele desperta sua curiosidade em manipulá-lo e dar significados a ele por meio do contexto da brincadeira (BROUGÈRE, 2010).

O tema exploração dos brinquedos industrializados evidenciou as diferentes maneiras utilizadas pelas crianças para se apropriarem desses brinquedos em suas brincadeiras. $\mathrm{Na}$ interação com esses objetos lúdicos, as crianças mostraram que há algo para além deles, que é sua imaginação e criatividade. Os objetos que estavam disponíveis pela instituição também se tornaram brinquedos e foram utilizados ora a partir da imagem e função que traziam, ora transformados em outros objetos, como elucidou o tema exploração de objetos.

Portanto, é de suma importância que as instituições de educação infantil invistam em brinquedos industrializados ou artesanais que possibilitem às crianças manipular, explorar e criar várias situações, brinquedos que fomentem as brincadeiras simbólicas, brinquedos de qualidade, de modelos e imagens variados e, também, objetos do cotidiano, desde que ofereçam segurança, para elas construírem suas brincadeiras e exercitarem ainda mais a criatividade.

Ao tratar sobre brinquedos, brincadeiras e materiais das crianças pequenas, o documento Brinquedos e Brincadeiras de Creches (BRASIL, 2012) indica a necessidade de selecionar objetos e materiais que provoquem a imaginação infantil. Corroborando com o assunto, Bomtempo (1999) esclarece que para estimular a curiosidade e imaginação da criança, o brinquedo não precisa ser eletrônico, automático e sofisticado, pois, em sua opinião, "o brinquedo sofisticado perde grande parte de suas qualidades lúdicas, por ser objeto acabado que limita a criatividade e a imaginação." (BOMTEMPO, 1999, p. 66).

Isso poderia facilitar o processo de aquisição de brinquedos e outros objetos lúdicos (como livros-brinquedo) de qualidade pelas instituições de educação 
infantil, pois sabemos que os brinquedos com mais dispositivos e funções têm um valor mais alto no mercado.

A apropriação dos brinquedos pelas crianças também oportunizou experiências referentes às relações de gênero, como apresentado no tema estereótipos de gênero. A ação delas, o modo como usaram e exploraram esses objetos, algumas vezes, desencadeou uma confirmação nos estereótipos de gênero muito presentes nos brinquedos industrializados. Esses brinquedos são portadores de cultura, dotados de um forte valor cultural (BROUGÈRE, 2010). No entanto, para além dos brinquedos, como as crianças são sujeitos sociais, compreende-se uma influência da sociedade, da cultura, dos valores da família, da mídia e das próprias práticas escolares nas ações estereotipadas.

É importante que o professor perceba que experiências são produzidas com brinquedos considerados socialmente como "inadequados" para meninos ou meninas e as incentive a brincar com todos os brinquedos. De acordo com o documento Brinquedos e Brincadeiras de Creches (BRASIL, 2012, p. 96), "Meninos e meninas devem ter a mesma oportunidade para brincar com tudo: carrinhos, bonecas, construção." Nesse sentido, Kishimoto (2010) afirma que é preciso que o professor crie um ambiente em que as crianças entrem em contato com os mais diferentes brinquedos, sem distinção de sexo, classe social ou etnia. O professor que fica passivo diante de situações de estereótipos de gênero está fazendo com que se reproduzam os preconceitos. É necessário aproveitar esses momentos das crianças de interação com os brinquedos e com seus pares, para fortalecer experiências não preconceituosas e estereotipadas, para problematizar com as crianças as situações vividas, questionando-as, instigando-as a (re)pensar e (re)significar.

Consideramos os momentos de brincar livre como sendo fundamentais na rotina das instituições de educação infantil, para que as crianças ampliem suas experiências brincantes. Ao se relacionarem com outras crianças e os vários brinquedos disponibilizados, elas podem adquirir e atribuir outros significados e enriquecer a cultura lúdica. A cultura lúdica é um conjunto de regras, características, significações próprias da brincadeira e que as crianças adquirem quando brincam (BROUGÉRE, 1998). Ao brincarem em casa, local onde muitas delas brincam sozinhas, meninos e meninas podem explorar apenas brinquedos destinados a fomentar práticas masculinas e femininas, caso a família tenha esse valor adquirido. Na instituição de educação infantil, as crianças têm oportunidade de brincar com brinquedos variados e diferentes daqueles que elas conhecem.

Contudo, para que isso ocorra, a presença e mediação pedagógica do professor é fundamental. Além do seu planejamento, o papel do adulto é essencial na 
escolha, organização e disponibilização dos objetos lúdicos, assim como o incentivo e o acompanhamento das brincadeiras infantis. Serão suas escolhas que influenciarão as brincadeiras das crianças e ampliarão a qualidade do brincar. Além disso, a disponibilização de outros ambientes para a efetivação da brincadeira é fundamental. Sobre isso, a presente pesquisa revelou um uso intensivo de sala para brincar, com pouca exploração de outros ambientes da instituição de educação infantil. "Um espaço estruturado, com mobiliário, brinquedos e materiais compatíveis com os temas das brincadeiras e enriquecido com a interação da professora, proporciona maior qualidade ao brincar." (BRASIL, 2012, p. 95).

Por isso, a importância de professores se atentarem à disponibilização dos objetos lúdicos, a fim de oportunizarem diversas brincadeiras, incentivarem a exploração, a curiosidade, a fantasia e a criatividade. A interação com os diferentes brinquedos e outros objetos que podem ser transformados imaginariamente em brinquedos possibilita às crianças vivenciarem inúmeras situações e experiências, contribuindo para a concretização de melhores oportunidades educativas para elas.

\section{REFERÊNCIAS}

BARDIN, L. Análise de conteúdo. 4. ed. Lisboa: Edições 70, 2009.

BOGDAN, R. C.; BIKLEN, S. K. Notas de campo. In: BOGDAN, R. C.; BIKLEN, S. K. (Org.). Investigação qualitativa em educação. Porto: Porto Editora, 1994. p. $150-175$.

BOMTEMPO, E. Brinquedo e educação: na escola e no lar. Psicologia Escolar e Educacional, v. 3, n. 1, p. 61-69, 1999.

BRASIL. Ministério da Educação. Secretaria da Educação Básica. Diretrizes Curriculares Nacionais para a Educação Infantil. Brasília, DF: MEC, SEB, 2010. Disponível em: <http://portal.mec.gov.br/index.php?option=com_docman\&task=doc_ download\&gid=9769\&Itemid $>$. Acesso em: 02 fev. 2017.

BRASIL. Ministério da Educação. Secretaria da Educação Básica. Brinquedos e Brincadeiras de Creches: manual de orientação pedagógica. Brasília, DF: MEC, SEB, 2012. Disponível em: <http://portal.mec.gov.br/component/content/ article?id=12579:educacao-infantil $>$. Acesso em: 18 fev. 2017.

BROUGÈRE, G. A criança e a cultura lúdica. Revista da Faculdade de Educação, São Paulo, v. 24, n. 2, jul./dez. 1998.

BROUGÈRE, G. Brinquedos e companhia. São Paulo: Cortez, 2004. 
BROUGÈRE, G. Brinquedo e cultura. 8. ed. São Paulo: Cortez, 2010.

COSTA, S. A. O Diário de Campo como dialética intersubjetiva. In: WHITAKER, D. C. A. (Org.). Sociologia Rural: questões metodológicas emergentes. Presidente Venceslau: Letras à Margem, 2002. p. 151-158.

FINCO, D. A educação dos corpos femininos e masculinos na Educação Infantil. In: FARIA, A. L. Go. de (Org.). O coletivo infantil em creches e pré-escolas: falares e saberes. São Paulo: Cortez, 2007. p. 94-119.

HORN, M. da G. S. Sabores, cores, sons, aromas: a organização dos espaços na educação infantil. Porto Alegre: Artmed, 2004.

KISHIMOTO, T. M. Brinquedos e brincadeiras na educação infantil. In: SEMINÁRIO NACIONAL: CURRÍCULO EM MOVIMENTO - PERSPECTIVAS ATUAIS, 1., 2010, Belo Horizonte. Anais... Belo Horizonte, 2010. p. 15-24.

KISHIMOTO, T. M. O jogo e a educação infantil. São Paulo: Pioneira Thomson Learning, 2003.

LEONTIEV, A. N. Os princípios psicológicos da brincadeira pré-escolar. In: VYGOTSKY, L. S.; LURIA, A. R.; LEONTIEV, A. N. (Org.). Linguagem, desenvolvimento e aprendizagem. 8. ed. São Paulo: Ícone, 2001. p. 46-58.

LUDKE, M.; ANDRÉ, M. E. D. A. Pesquisa em educação: abordagens qualitativas. São Paulo: EPU, 2012.

MINAYO, M. C. de S. Ciência, técnica e arte: o desafio da pesquisa social. In: MINAYO, M. C. de S. (Org.). Pesquisa Social: teoria, método e criatividade. Petrópolis: Vozes, 1994. p. 9-29.

OLIVEIRA, M. W. Pesquisa e trabalho profissional como espaços e processos de humanização e de comunhão criadora. Caderno CEDES, Campinas, v. 29, n. 79, p. 1-7, set./dez., 2009.

OLIVEIRA, P. de S. O que é brinquedo. 3. ed. São Paulo: Brasiliense, 2010.

PEREIRA, R. M. R.; SALGADO, R. G.; JOBIM E SOUZA, S. Pesquisador e criança: dialogismo e alteridade na produção da infância contemporânea. Cadernos de Pesquisa, v. 39, n. 138, p. 1019-1035, set./dez., 2009.

SARMENTO, M. J. As culturas da infância nas encruzilhadas da $\mathbf{2}^{\mathbf{a}}$ modernidade. Braga: Instituto de Estudos da Criança, Universidade do Minho, 2003. 
SILVA, J. P. da; BARBOSA, S. N. F.; KRAMER, S. Questões teórico-metodológicas da pesquisa com crianças. In: CRUZ, S. H. V. (Org.). A criança fala: a escuta de crianças em pesquisas. São Paulo: Cortez, 2008. p. 23-32.

SOMMERHALDER, A.; ALVES, F. D. Jogo e a Educação da Infância: muito prazer em aprender. Curitiba: CRV, 2011.

Recebido em: 02 de maio de 2017 Aceito em: 29 de agosto de 2017

Endereço para correspondência: Rodovia Washington Luís, Km 235, SP-310, Guanabara, 13565-905, São Carlos, São Paulo, Brasil; sommeraline1@gmail.com 